удК: 81 '272

\title{
О.А. Культепина
}

\section{СОЦИОЛИНГВИСТИЧЕСКОЕ ИССЛЕДОВАНИЕ ГОРОДСКОЙ ЛЕКСИКИ ТВЕРИ}

\begin{abstract}
Приводятся результаты социолингвистического эксперимента 2015-2016 гг., целью которого было выяснить степень влияния экстралингвистических факторов на распознавание и использование лексики города Твери местными жителями. Предпосылкой для исследования стало предположение о возможном изменении в составе региональной лексики и ее постепенном разрушении в речи молодых образованных тверичей под влиянием внешних социальных факторов (высокая мобильность, образование, интернет-коммуникация).

Ключевые слова: региональная лексика; лексика города; регионализмы; региолект; социолингвистика.
\end{abstract}

\section{К вопросу об исследовании лексики города}

Целью настоящей работы являются выявление и анализ социальных факторов, влияющих на узнавание и употребление тверской регионально маркированной лексики, или лексических регионализмов. Кроме того, исследование определяет текущее состояние региональной лексики города Твери и отвечает на вопрос, находится она на стадии разрушения или нет. Одной из гипотез, мотивировавших выбор модели эксперимента, стало предположение, что высокая мобильность молодых тверичей может указать на процесс постепенной утраты регионализмов в Твери из-за влияния других региональных вариантов и литературной нормы.

Понятие лексики города используется как условное обозначение лексики, относящейся к региональному варианту русского языка и бытующей в среде городских жителей, без спецификации в языке определенной социальной группы (например, детей, студентов и др.). Для работы интерес представляли только городские регионально окрашенные слова, которые принадлежат так называемой региональной норме и которые:

- присутствуют в разговорной речи образованного слоя городского населения, тех носителей региональной нормы, кого в регионе считают грамотными носителями русского языка [1];

- ощущаются носителями как уникальные единицы лексики определенного региона;

- не принадлежат исключительно одной закрытой социальной группе и, как правило, не имеют яркой жаргонной окраски (ср.: научка в значении «научная библиотека при ТвГУ» (студенческая среда) или разупыриться в значении «долго и нудно жаловаться на что-либо, как правило, необоснованно» (жаргон));

- могут быть использованы в СМИ наравне с общеупотребительной нейтральной лексикой (необязательно).

Вопрос о научной ценности исследования языка города в 1970-1980-е гг. поднимали Е.А. Земская, Л.А. Капанадзе, а ранее - Б.А. Ларин, которые составили классические работы по этой проблематике. Сегодня эта тема особенно актуальна в связи с изучением языкового существования крупных городов с развитой социальной стратификацией [2-5]. И.А. Букринская и О.Е. Кармакова [6] приводят целый ряд фамилий исследователей, которые в свое время занимались изучением речи крупных городов (Вологды, Екатеринбурга,
Курска, Новосибирска, Нижнего Новгорода, Перми, Ростова-на-Дону, Саратова и др.).

И все же, как правило, исследователей интересует именно сама лексика и ее положение в отношении к литературной норме русского языка. В работах может описываться состояние городской лексики или ее отдельного сегмента (например, микротопонимы), проводиться сравнительный анализ лексики нескольких городов. В целом в указанных выше исследованиях представлена фиксация актуального состояния городской лексики без особого акцентирования на взаимосвязи с конкретным городским языковым сообществом или на возможных источниках изменений в регионально окрашенной лексике. Лексика города рассматривается независимо от влияния социальных факторов (пола, возраста, образования) на ее развитие в речи городских жителей. Из известных работ, демонстрирующих социолингвистический подход к изучению лексики города, можно назвать проект А.И. Матвеева «Регионализмы в городской речи сибиряков» [4] и изданный в 2015 г. «Словарь региональной лексики и народных топонимов города Новосибирска» [7].

В отношении Твери можно с уверенностью утверждать, что никто не интересовался городской лексикой в социолингвистическом контексте. Широко известен среди диалектологов и лексикографов многотомный «Тематический словарь тверских городов», изданный под редакцией Т.В. Кирилловой и Л.Н. Новиковой в 2002-2006 гг. [8], однако лексика городских жителей и экстралингвистические факторы влияния на нее не попадали в поле внимания исследователей.

Отдельно необходимо сказать о терминологии исследования в работе следующих определений:

- региолект вслед за А.С. Гердом [9] интерпретируется как «особая форма устной речи, в которой уже утрачены многие черты диалекта, развились новые особенности. Это форма, с одной стороны, не достигшая еще статуса литературного языка, а с другой, в силу наличия многих ареально варьирующихся черт, не совпадающая полностью и с городским просторечием» [9. С. 23];

- лексический регионализм - специфические для конкретного города лексические единицы, которые активно используются жителями города вне зависимости от их социального, профессионального и другого статуса [10]; 
- городское просторечие - разговорно-обиходная речь необразованных городских слоев.

\section{Двухуровневый эксперимент: модель, выборка и результаты}

Для решения исследовательских задач был подготовлен эксперимент, состоящий из двух социолингвистических опросов, проведенных с промежутком примерно в четыре месяца. В первом опросе целевой группой стали тверские респонденты - коренные жители города или проживающие здесь с детских / юношеских лет. Опрос должен был проверить гипотезу, действительно ли пол, возраст, образование и мобильность влияют на узнавание / употребление и успешное / неуспешное определение происхождения лексических регионализмов в среде тверичей.

Второй частью эксперимента также стал онлайнопрос. Задача на этом этапе состояла в том, чтобы понять, насколько успешно молодые информанты из трех городов Центральной России - Москвы, Твери и Санкт-Петербурга - сегодня определяют «свои» и «чужие» регионализмы и насколько сильно смешались региональные нормы в речи молодежи. Необходимость проведения второго опроса может быть объяснена несколькими причинами. Во-первых, включение иных региональных групп позволило провести сравнительный анализ и понять, действительно ли тверские регионализмы имеют региональный статус или они известны и за пределами Твери и Тверской области и потеряли свою ареальную специфику. Такое сомнение объясняется отсутствием каких-либо списков или словарей регионализмов Твери. Во-вторых, было интересным выяснить, существуют ли вообще в употреблении молодежи регионализмы и ощущают ли они их как таковые или употребляют, не задумываясь об их региональном происхождении. Группы из Москвы и СанктПетербурга были выбраны потому, что между этими городами и Тверью существуют активные контакты и, следовательно, можно было бы ожидать достаточно сильного смешения всех трех региональных словарей.

После проведения первого опроса был сформирован список регионализмов, которые большинство респондентов определяли как исконно тверские и которые в дальнейшем были использованы во втором опросе. Суть в том, что не все регионализмы ощущаются носителями как таковые, и тогда логично встает вопрос об их регионально-специфическом статусе. Именно поэтому по результатам первого опроса было необходимо составить список слов, регионально маркированный статус которых был бы признан наибольшим количеством респондентов и не вызывал бы сомнений.

\section{Первый опрос: регионализмы в речи группы тверских респондентов}

Опросник состоял из двух частей - социологической и собственно лингвистической. Первая пред- ставляла собой анкету респондента, в которой он(а) указывал(а) личные данные: пол, возраст, место рождения, происхождение родителей, частоту поездок в другие области, место отдыха на каникулах в детстве, образование и профессиональную деятельность. Всего анкета содержала 11 обязательных вопросов и 3 дополнительных.

Для первого опросника был создан контрольный список регионализмов для предъявления респондентам. Список состоял из 40 тверских регионализмов и 18 филлеров (от англ. filler - лексическая единица, которая вводится в эксперимент для «отвлечения» внимания респондентов от проверяемых для гипотезы слов). Во многом идеи для составления списка первого опроса дали работы западных социолингвистов по regional vocabulary и regional levelling, использовавших тематические региональные списки [11], толкования регионализмов без их озвучивания [12] и методы интроспекции [13]. Однако ни одна из методик не могла идеально подойти поставленным исследовательским задачам. Поэтому после анализа опыта иностранных исследователей и доступных словарей и проектов словарей русских регионализмов был выбран компромиссный вариант. Часть списка была собрана методом мини-опроса коренных жителей Твери старшего возраста, которые наиболее вероятно могли быть носителями особой региональной нормы. Другая часть была найдена в обсуждениях на форуме «Городские диалекты» [14]: некоторые регионализмы были взяты прямо из тематических рубрик, а другие найдены благодаря приведенным толкованиям интроспективным путем. Все предполагаемые регионализмы были еще раз проверены через систему Wordstat Яндекса, которая показывала географию запросов за последний месяц (ноябрь-декабрь 2015 г., январь 2016 г.), а также на самом форуме «Городские диалекты» и в некоторых доступных словарных статьях. При проверке в словаре [15] значимым подтверждением регионально маркированного статуса являлись либо специальные пометы рядом со словом, либо само отсутствие словарной статьи для регионализма.

Как верно отмечает В.И. Беликов, для успешного поиска распространенных регионализмов единственным выходом остается «целенаправленный поиск межрегиональных лексических различий в определенных лексических полях» [16. С. 43]. Именно поэтому при составлении списков в качестве ориентиров для поиска были выбраны тематические поля, связанные с детством, повседневностью и бытом, городским транспортом, учебными заведениями, общественными местами. Отдельно следует сказать о добавлении в список урбанонимов - «внутригородских топонимов» [17. С. 34], включающих названия микрорайонов, знаковых городских достопримечательностей и мест.

Конечный список для первого опроса приведен в табл. 1. В первой колонке даны регионализмы, которые предъявлялись респондентам без контекста, в одиночной позиции, а во второй - те регионализмы, которые были даны в контексте (например: «А власти в очередной раз нахомутали налоги»). 
Также в проверочный список были добавлены 18 филлеров: бадейка, бадлон, барахло, баркан, ватора, гараж-ракушка, глобка, депо, исподники, катуль, киоск, крупень, поребрик, посудник, пьшка, пятнашки, трясель, шанежки (или шанешки). Необходимо оговориться, что филлеры также были отобраны целенаправленно. Все они относятся или к диалектам Тверской области, или к регионально окрашенной лексике Москвы и Санкт-Петербурга. Поэтому в результате весь предложенный проверочный список имел только регионально (диалектно) окрашенную лексику в составе. Хотя, разумеется, московские регионализмы во многом не могли быть восприняты как таковые из-за общей ориентации литературной лексической нормы на московскую (обсуждение этого вопроса см. в [3]).

Контрольный список регионализмов, использованных в первом опросе

\begin{tabular}{|c|c|}
\hline Регионализмы без контекста & Регионализмы в контексте \\
\hline 1. Брязгаться & 1. Большая \\
\hline 2. Горбатка & 2. Бомж-пакет \\
\hline 3. Горсад & 3. Буранька \\
\hline 4. Дебиловка & 4. Ведра \\
\hline 5. Камень-ножницы-бумага & 5. Гадюшник \\
\hline 6. Лягушатник & 6. Догонялки \\
\hline 7. Маршрутчик & 7. Игровуха \\
\hline 8. Матюкаться & 8. Кулек \\
\hline 9. Пара-выра-за-себя & 9. Лягушатник \\
\hline 10. Рыгаловка & 10. Нахомугали \\
\hline 11. Склитка & 11. Пара-выра-за-себя \\
\hline 12. Сосалка & 12. Рюмка \\
\hline 13. Сотик & 13. Свечка \\
\hline 14. Стерка & 14. Сотик \\
\hline 15. Схудилось & 15. Таз \\
\hline 16. Тянучки & 16. Трамвайный дрифт \\
\hline 17. Учага & 17. Тянучки \\
\hline 18. Фишка & 18. Фишка \\
\hline 19. Формовка & 19. Формовка \\
\hline 20. Электра & 20. Шайба \\
\hline
\end{tabular}

На основе проверочного списка респондентам предлагалось выполнить два задания: указать степень «знакомства» с приведенными словами (собственное употребление / узнавание регионализмов) и предположить их происхождение (табл. 2). При этом одни слова были даны без контекста, а другие стояли в одиночной позиции и / или в контексте. Таким образом были сняты возможные затруднения, связанные с многозначностью некоторых слов, которые вне предложения могли быть восприняты как слова из литературного русского языка (например, ведра, свечка, таз, рюмка, шайба).

Вопросы к контрольному списку первого опроса

\begin{tabular}{|c|c|}
\hline Употребление и узнавание слов & Происхождение слов \\
\hline $\begin{array}{l}\text { - Да, знаю, понимаю и употребляю } \\
\text { - } \quad \text { Знаю и понимаю, но никогда не употребляю } \\
\text { - } \quad \text { Знаю и понимаю, ранее употреблял (в детстве, в } \\
\text { юношестве) } \\
\text { - } \text { Не знаю и не понимаю, но догадываюсь } \\
\text { - Не понимаю и не догадываюсь }\end{array}$ & $\begin{array}{ll}\text { - } & \text { Тверь } \\
\text { - } & \text { Тверь и Тверская область } \\
\text { - } & \text { Местное слово из других городов и } \\
\text { областей } \\
\text { - Общеупотребительное русское слово } \\
\text { - Другое }\end{array}$ \\
\hline
\end{tabular}

В опросе принимали участие респонденты, проживающие в городе Твери и в Тверской области, но для исследования релевантными являлись только те, кто родился и / или вырос в Твери. Было важно за- 
фиксировать результаты именно тех респондентов, чей период освоения языка (language acquisition) прошел в языковой среде этого города. При этом в работе принимается точка зрения некоторых социолингвистов-исследователей языковых изменений во времени [18]: формирование языковой личности может длиться не до 12-13, а до 17-18 лет. Именно поэтому при анализе также принимались во внимание ответы тех респондентов, кто переехал в Тверь для обучения в вузе в возрасте шестнадцати или семнадцати лет.

В итоге для анализа были отобраны ответы только 54 респондентов в возрасте от 13 до 63 лет. Эта выборка дала две большие возрастные группы: 27 человек младше 25 лет и 27 человек старше 25 лет. Возрастной порог разделяет всех респондентов на группу тех, кто родился и вырос в СССР, и группу тех, чье детство прошло после его распада в 1991 г. Такое разграничение информантов было обосновано предположением, что региональные особенности речи детей, выросших в постсоветскую эпоху, должны были попасть под сильное влияние массовых коммуникаций: телевидение, даже местное, передавало литературную норму русского языка, а не региональную [19. С. 210-219]. На изменение региональных особенностей речи мог повлиять и фактор мобильности респондентов. Хотя Тверь и до 1991 г. находилась на активном транспортном участке Санкт-Петербург - Москва, развитие железнодорожного сообщения и увеличение числа электропоездов на Октябрьской железной дороге изменили жизнь молодых тверичей. Так, для респондентов, которым сейчас 20-25 лет, вполне привычно было в старшем школьном возрасте на выходные выезжать в Москву и Московскую область.

Ориентируясь на эти факты, большая языковая изолированность была предположена у тверичей старше 25 лет, которые не имели в юношеские годы возможность часто выезжать из Тверской области или находиться в межрегиональном языковом сообществе, не покидая пределов Твери.

Первый опрос прошли 19 мужчин и 35 женщин. Из них коренные жители составили 23 человека (14 женщин и 9 мужчин) в группе младше 25 лет и 17 человек (9 женщин и 8 мужчин) в группе старше 25 лет.

\section{Анализ результатов первого опроса}

Предварительное замечание: при анализе были использованы условные сокращения: УУ - для обозначения параметра употребления / узнавания регионализмов (данные, полученные из ответов по первому заданию к контрольному списку), П - для обозначения параметра корректного определения происхождения регионализма (второе задание). Сумма за параметр складывалась следующим образом: максимальное число 5 означало, что респондент не понимает и не догадывается о значении слова-стимула (для параметра УУ) и не знает его происхождения (для параметра П), а минимальное 1 зашифровывало положительный ответ для любого из параметров. Таким образом, респонденты с меньшими суммами по обеим переменным более часто употребляют и узнают регионализмы и более успешно определяют их происхождение. Как можно судить из графика, представленного на рис. 1, употребление / узнавание по всей когорте редко превышает $50 \%$. В случае определения происхождения (рис. 2), наоборот, большинство ответов набрали более $50 \%$, и только 5 респондентов не перешли порог $50 \%$ или остановились у его черты. Следовательно, в большинстве случаев тверичи плохо распознают региональный статус регионализмов, т.е. могут спутать их со словами другого региона или, что чаще, со словами из литературного русского языка.

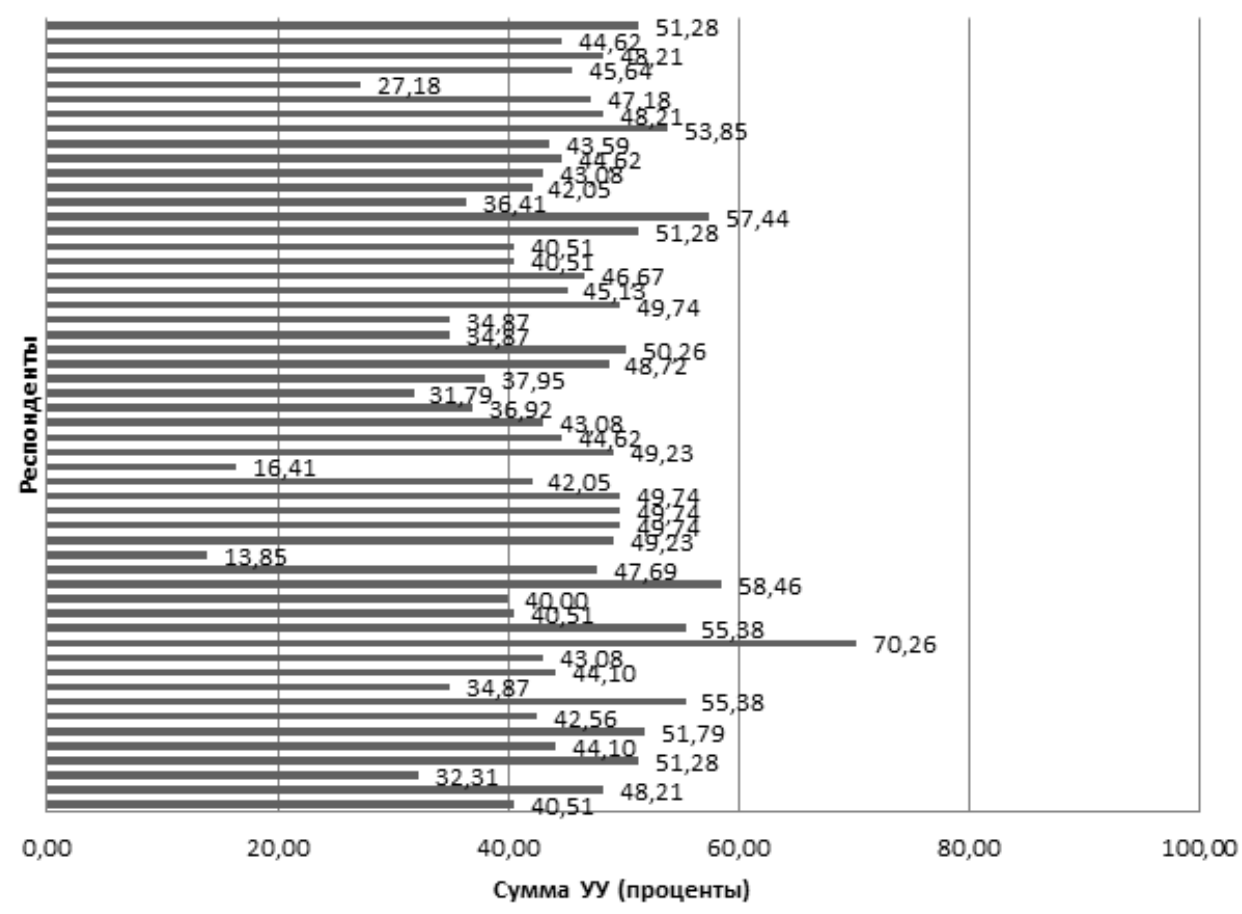

Рис. 1. Сумма УУ (употребление / узнавание) по респондентам 


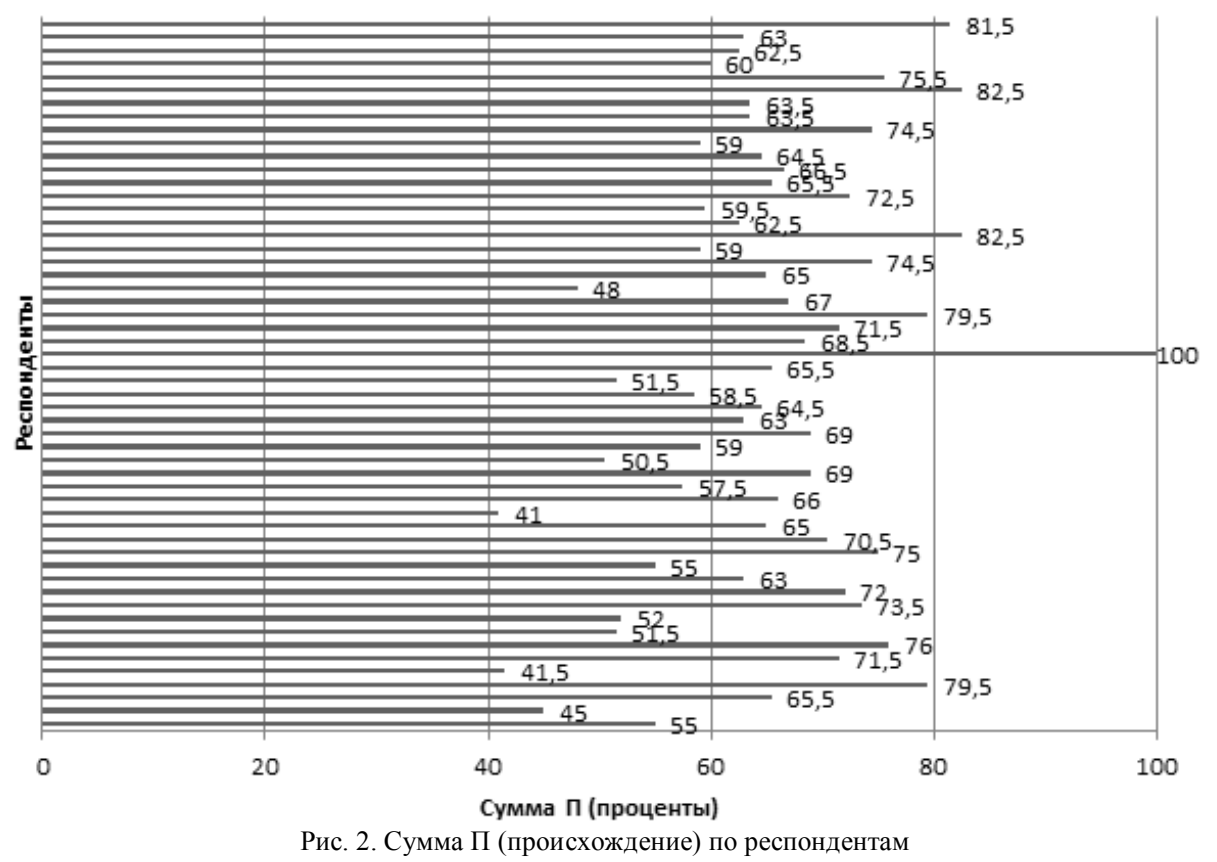

Основным методом анализа полученных в эксперименте данных служил регрессионный анализ, который должен был показать, какие социальные факторы могут предсказать употребление / узнавание и определение / происхождение регионализмов. Кроме того, важным было то, что при использовании регрессии происходит проверка, соответствует ли реальной ситуации построенная модель зависимости одной переменной от ряда предикторов (внешних факторов влияния) и их попарных взаимодействий. Таким образом, регрессионный анализ позволял взглянуть на разные модели влияния экстралингвистических факторов на переменные УУ и П.

При регрессионном анализе зависимой переменной выступали сначала УУ, потом П, а предсказывающими переменными выступали пол, возраст, мо-

бильность и образование - все вместе и попарно. При этом для первой модели (по УУ) формула была сформирована таким образом, чтобы предсказывающие переменные не только показали влияние на зависимую по отдельности, но и сразу в паре с другими параметрами.

Регрессионный анализ четырех независимых переменных, предположительно предсказывающих функционирование УУ, показал, что никакие параметры не влияют ни поодиночке, ни при взаимодействии, а доля объясненной дисперсии, т.е. соответствие построенной модели реальной, вообще является отрицательной (табл. 3). То есть невозможно объяснить УУ влиянием всех четырех параметров во взаимодействии, значит, модель неудачная и не может объяснить реальное распределение.

Т а бли ц а 3

Регрессионный анализ по модели с зависимой переменной УУ

\begin{tabular}{|c|c|c|c|c|c|}
\hline \multirow{13}{*}{$\begin{array}{l}\text { Анализ влияния } \\
\text { каждого } \\
\text { параметра на Уу }\end{array}$} & & Estimate & Std.Error & t value & $\operatorname{Pr}(>|t|)$ \\
\hline & (Intercept) & 114.02444 & 47.85339 & 2.383 & $0.0217^{*}$ \\
\hline & Пол & -13.41547 & 40.89643 & -0.328 & 0.7445 \\
\hline & Возраст & -0.87145 & 1.30004 & -0.670 & 0.5062 \\
\hline & Мобильность & -2.61396 & 6.22011 & -0.420 & 0.6764 \\
\hline & Мобитьность & -2.15178 & 8.12226 & -0.265 & 0.7923 \\
\hline & Пол:Возраст & -0.22388 & 0.64298 & -0.348 & 0.7294 \\
\hline & Пол:Мобильность & 2.76445 & 5.16932 & 0.535 & 0.5956 \\
\hline & Пол:Образование & -0.79975 & 3.93192 & -0.203 & 0.8398 \\
\hline & Возраст:Мобильность & 0.05671 & 0.15432 & 0.368 & 0.7150 \\
\hline & Возраст:Образование & 0.06319 & 0.09507 & 0.665 & 0.5098 \\
\hline & Мобитьность:Образование & 0.25337 & 1.11657 & 0.227 & 0.8216 \\
\hline & \multicolumn{4}{|c|}{ 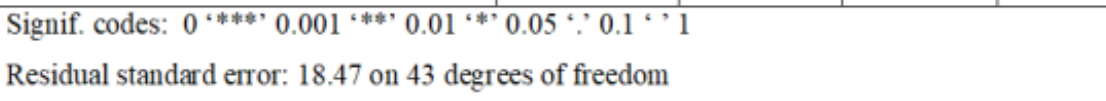 } & \\
\hline
\end{tabular}


Результаты анализа парных регрессионных моделей для УУ

\begin{tabular}{|l|c|c|}
\hline Модель взаимодействия & p-value модели & R-squared модели \\
\hline УУ $\sim$ Возраст + Пол & 0.1357 & 0.1041 \\
\hline УУ $\sim$ Возраст + Образование & 0.3862 & 0.05835 \\
\hline УУ $\sim$ Возраст + Мобильность & 0.2093 & 0.08587 \\
\hline УУ $\sim$ Пол + Образование & 0.6635 & 0.03085 \\
\hline УУ Пол + Мобильность & 0.4408 & 0.052 \\
\hline УУ Мобильность + Образование & 0.5927 & 0.03699 \\
\hline
\end{tabular}

При изменении параметров модели (исключении парного влияния социальных параметров) данные регрессионного анализа также указывают на большую вероятность отсутствия влияния: данные $\operatorname{Pr}(>|\mathrm{t}|)$ варьируются от 0,147 (Мобильность) до 0,587 (Образование), что не имеет статистической значимости.

Далее был построен ряд регрессионных моделей с УУ в качестве зависимой переменной (УУ пол / возраст / мобильность / образование в попарном взаимодействии). Все проведенные анализы также показали отсутствие какой-либо значимой статистической связи между парами параметров и УУ (табл. 4): p-value > 0,05 или > 0,5 и R-квадрат меньше 0,5.

По регрессионному анализу зависимости П от всех разобранных социальных параметров (табл. 5) видно, что мобильность $(\operatorname{Pr}(>|t|)=0.0384 *)$ обладает некоторой значимой способностью предсказать П лексических регионализмов. Поэтому есть основания утверждать, что мобильность в некоторой степени влияет на знание происхождения регионализмов.

Регрессионный анализ по модели с зависимой переменной П

\begin{tabular}{|c|c|c|c|c|c|}
\hline \multirow{7}{*}{$\begin{array}{l}\text { Анализ } \\
\text { влияния } \\
\text { каждого } \\
\text { параметра на } \\
\text { П }\end{array}$} & & Estimate & Std. Error & t value & $\operatorname{Pr}(>|t|)$ \\
\hline & (Intercept) & 101.1969 & 15.0725 & 6.714 & $1.84 \mathrm{e}-08^{* * *}$ \\
\hline & Пол & 5.8264 & 6.2076 & 0.939 & 0.3525 \\
\hline & Возраст & 0.1870 & 0.3138 & 0.596 & 0.5539 \\
\hline & Мобильность & 3.9503 & 1.8565 & 2.128 & $0.0384 *$ \\
\hline & Образование & -1.2515 & 1.8096 & -0.692 & 0.4925 \\
\hline & \multicolumn{5}{|c|}{$\begin{array}{l}\text { Signif. codes: } 0 \text { '***' } 0.001 \text { '**' } 0.01 \text { '*' } 0.05 \text { ', } 0.1 \text { “' } 1 \\
\text { Residual standard error: } 21.65 \text { on } 49 \text { degrees of freedom } \\
\text { Multiple R-squared: } 0.1077, \quad \text { Adjusted R-squared: } 0.03483 \\
\text { F-statistic: } 1.478 \text { on } 4 \text { and } 49 \text { DF, p-value: } 0.2232\end{array}$} \\
\hline
\end{tabular}

Однако множественные модели имеют погрешности из-за использования нескольких факторовпредикторов. Как видно из табл. 6, где представлены попарные модели, никакой социальный параметр не показывает статистически значимых результатов. Хо- тя модель взаимодействия Пол + Мобильность и демонстрирует самые лучшие из всех представленных показатели (p-value $>0,05$ и R-квадрат $>0,1$ ), этих данных недостаточно, чтобы утверждать какое-либо значимое влияние.

Результаты анализа парных регрессионных моделей для П

\begin{tabular}{|l|c|c|}
\hline Модель взаимодействия & p-value модели & R-squаred модели \\
\hline П $~$ Возраст + Пол & 0.7447 & 0.02416 \\
\hline П $\sim$ Возраст + Образование & 0.8671 & 0.01427 \\
\hline П $~$ Возраст + Мобильность & 0.7791 & 0.02138 \\
\hline П $\sim$ Пол + Образование & 0.4488 & 0.05112 \\
\hline П $\sim$ Пол + Мобильность & $\mathbf{0 . 1 4 6 5}$ & $\mathbf{0 . 1 0 0 9}$ \\
\hline П $\sim$ Мобильность + Образование & 0.5158 & 0.0442 \\
\hline
\end{tabular}

Таким образом, можно сделать вывод, что в рассматриваемой выборке на региональную лексику ин- формантов не имеет значимого влияния ни один из проверенных социальных факторов. 


\section{Второй опрос: регионализмы трех городов и межрегиональные группь}

Этот опрос должен был проверить, насколько успешно информанты из трех различных городов определяют «свои» и «чужие» регионализмы и как часто употребляют их в собственной речи. Важной задачей было понять, насколько сильно смешались три региональные нормы в среде молодежи и использует ли конкретно тверская молодежь регионально окрашенную лексику.

Второй опрос во многом повторял вопросы первого, однако их количество было уменьшено (убраны вопросы о родителях, окружении и поездках). Но вместо них был добавлен вопрос об актуальном месте жительства (так как опрос был ориентирован на жителей разных городов), а также вопрос на оценку присутствия лексических регионализмов в собственной речи. Ответ на него предположительно мог бы показать уровень осознанности употребления регионализмов в речи респондентов. При анализе этот вопрос был преобразован в отдельный параметр (Рефлексия), по которому можно было бы оценить УУ и П регионализмов в зависимости от сознательной установки на употребление / неупотребление региональной лексики.

Контрольный список для второго опроса претерпел значительные изменения. Так как целью этого опроса была проверка узнавания своей / чужой региональной лексики, то три группы регионализмов - из Твери, Москвы и Санкт-Петербурга - служили друг для друга филлерами. Если московские и питерские регионализмы были собраны в основном из словарей и в меньшей степени из обсуждений форума «Городские диалекты», то формирование списка тверских регионализмов для этого этапа было более сложным. По окончании первого опроса тверские регионализмы были ранжированы по сумме корректных ответов на вопрос о происхождении, и из полученного списка были отобраны региональные городские регионализмы с наибольшими суммами по верному ответу «Тверь» или «Тверская область», включая: большая (комната) (10), бомж-пакет (7), брязгаться (9), буранька (17), ведра (7), гадюшник (8), горбатка (43), горсад (31), дебиловка (11), догонялки (3), игровуха (9), кулек (26), лягушатник (13), маршрутчик (5), матюкаться (7), нахомутать (12), пара-выра-за-себя (16), рыгаловка (8), рюмка (28), свечка (41), склитка (12), сосалка (8), сотик (24), схудилось (9), таз (5), трамвайный дрифт (23), тянучки (9), учага (15), шайба (38), электра (9).

Однако из дальнейшего тестирования были исключены урбанонимы и характерное для Твери выражение трамвайный дрифт как абсолютно неизвестные за пределами города и потому не представляющие ценности для анализа межрегиональных групп. Кроме того, слова большая (в значении «большая комната») или дебиловка, несмотря на достаточно высокую сумму правильных ответов, не были добавлены в список второго опроса: первая из-за слишком неясного значения, отмеченного многими респондентами, а вторая из-за возможной жаргонной окраски, которая была подтверждена информантами старшего возраста.

Второй опрос прошли три группы информантов, разделенных по происхождению: из Твери, Москвы и Санкт-Петербурга. Ограничения на социальные параметры информантов для этого были более строгими по сравнению с первым. Главной целью отбора респондентов для второго опроса была возможная наибольшая корректность данных на небольшой однородной выборке, поэтому для анализа были отобраны только ответы молодых женщин (так как составляли большую часть респондентов, использующих регионализмы в своей речи), родившихся или давно живущих в указанных городах. В результате по второму опросу сформировались три когорты информантов по 10 женщин из Москвы, СанктПетербурга и Твери в возрасте от 21 до 35 лет. При этом только в тверской когорте оказались две респондентки, проживающие в Твери с 8 и 16 лет соответственно, а также три коренные тверичанки, которые на сегодняшний день живут в других городах. Две остальные группы составили проживающие на данный момент в родном городе респонденты. Средний показатель по возрасту составил 24,7 лет, что вполне соответствовало требованиям проверки гипотезы: объектом рассмотрения должны были быть молодые респонденты (рис. 3).

Следует отметить, что возрастные ограничения также выровняли и показатели по образованию: все респонденты либо уже получили высшее образование, либо еще проходят обучение в университете и часто подрабатывают. Такая гомогенность была полезна для опроса, так как максимально уравнивала группы респондентов.

\section{Анализ данных по второму опросу}

При анализе второго опроса главной целью всех примененных статистических тестов было выяснить, как в группе молодых респондентов параметр происхождения влияет на употребление / узнавание регионализмов и на определение их происхождения, а кроме того, понять, есть ли связь между возрастом, происхождением и употреблением / узнаванием и определением происхождения регионализмов.

Происхождение и регионализмы. Первая проверка, связанная с происхождением респондентов, должна была указать, какие регионализмы имеют наибольшую зависимость по переменной УУ или П от происхождения информантов. Анализ показал, какое соотношение существует между УУ и П разных региональных слов и происхождением респондентов, благодаря чему оказалось возможным определить, какая группа регионализмов лучше всего идентифицируется информантами как «чужая». Наибольшую связь между УУ и происхождением респондентов показали тверские регионализмы, что еще раз подтверждает региональный статус этих слов, в отличие, например, от московских регионализмов, которые определяются как регионально специфичные гораздо хуже, на что указывает незначимая статистическая связь между УУ и параметром (табл. 7). 
Стабильную связь между УУ/П и происхождением респондента показывают питерские регионализмы, которые тоже успешно определяются как «чужие» московской и тверской группой и, соответственно, как «свои» - питерской. Происхождение московских регионализмов информанты определяют достаточно плохо (p-value $\geq 0,05$ ). Никакой статистически значимой связи не было обнаружено между П и происхождением респондентов. Это означает, что все респонденты определяют происхождение регионализмов одинаково, независимо от собственного происхождения.
Остановимся подробнее на тверских регионализмах и причинах невысокого процента П этих слов в группе самих тверичей. Как можно видеть из табл. 8, наименьшая сумма по употреблению / узнаванию тверских регионализмов ожидаемо принадлежит группе тверских респондентов, из чего следует, что они чаще всех понимают и употребляют эти регионально окрашенные слова. Но при этом они хуже всех определяют региональный статус тверских регионализмов (наименьшая сумма корректных ответов по П): часто путают их с общеупотребительными словами или (реже) «чужими» регионализмами.

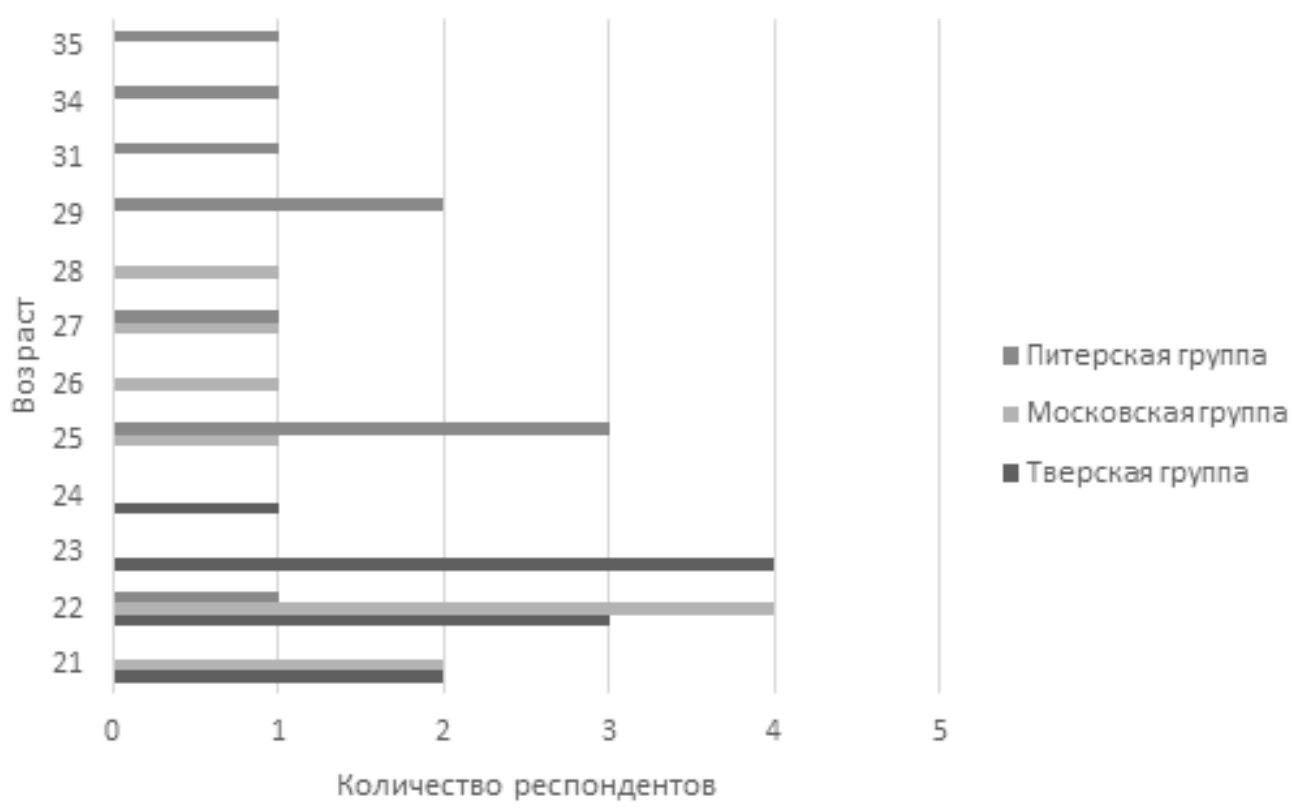

Рис. 3. Сравнение когорт для второго опроса

Корреляционный анализ трех групп регионализмов

\begin{tabular}{|l|l|l|l|}
\hline Регионализмы & P-value (Уу) & P-value (I) & Вывод \\
\hline Тверские & 1 е-04 & 0.8965 & $\begin{array}{l}\text { Наличие значимой связи с Уу и практически } \\
\text { отсутствие связи с П }\end{array}$ \\
\hline Московские & 0.269 & 0.05145 & $\begin{array}{l}\text { Налнчне достаточно хорошей связи с П и слабой с } \\
\text { уу }\end{array}$ \\
\hline Питерские & 0.008949 & 0.0008429 & Налнчне статистически значимых связей с Уу и П \\
\hline
\end{tabular}

Данные по переменной УУ и П и происхождение респондентов (тверские регионализмы)

\begin{tabular}{|l|l|l|}
\hline Информанты & Сумма (Уу) & Сумма (II) \\
\hline Тверские & 334 & 38 \\
\hline Московские & 492 & 55 \\
\hline Питерские & 498 & 40 \\
\hline & $\begin{array}{l}\text { Чем больше сумма по Уу, тем меньше респонденты употребляют данные } \\
\text { регионализмы. Чем больше сумма по П, тем больше верньх ответов по } \\
\text { пронсхождению тверских регионализмов дали респонденты }\end{array}$ \\
\hline
\end{tabular}


Можно предположить, что москвичи и питерцы лучше определяют региональный статус тверских регионализмов именно из-за того, что, не используя эти слова в своей речи, идентифицируют их тверское происхождение методом исключения. Это вполне вероятное объяснение при условии, что региональная лексическая норма двух столиц в какой-то степени известна среди московских и питерских респондентов. Именно поэтому они могли легче определить тверское происхождение регионализмов, в отличие от самих тверичей, которые не могут провести границы между «своими» регионализмами и «чужими» или общеупотребительными словами.

Вывод о высокой степени зависимости УУ от происхождения информанта и о низкой предсказываемости П по тому же параметру подтверждают и данные регрессионного анализа. При отличном показателе действия модели УУ тверских регионализмов происхождение информанта (p-value $=1 \mathrm{e}-04)$ регрессионная модель зависимости от происхождения респондента никак не может объяснить П (p-value $=0.8965)$.

Регрессионная модель для второго опроса: влияние предикторов на социолингвистические переменные УУ и П. Регрессионная модель, предсказывающая зависимость социолингвистических переменных (УУ или П) от социальных параметров, была построена на основе всех собранных данных из анкет информантов (при этом регионализмы из трех городов рассматривались вместе). Предполагалось, что если какие-то значимые параметры не были рассмотрены отдельно, то регрессионный анализ укажет на них. Поэтому были включены следующие параметры: возраст, происхождение, мобильность (состоящая из параметров «переезд» и «каникулы»), образование, деятельность и рефлексия. Предсказывающую силу в этом анализе показал только параметр происхождения информантов $\left(\operatorname{Pr}(>|t|)=0.046709^{*}\right)$, остальные, как и в случае с первым опросом, не показали какого-либо результата.

При регрессионном анализе с П в роли зависимой переменной стало понятно, что параметр регионального происхождения информанта также показывает один из самых высоких результатов. Но в общем статистически этот параметр незначим (p-value $=0.383)$ и не может указывать на значимую зависимость между ним и П. Р-value модели при этом составило всего 0.2767 , а доля объясненной дисперсии - всего 0,03596, что указывает на слабую предсказывающую силу модели. Таким образом, можно резюмировать, что в отношении зависимой П регрессионная модель не смогла выявить реальные факторы влияния.

\section{Выводы}

Из отобранных для эксперимента 54 тверичей ни один из предложенных социальных параметров не показал статистически значимых результатов, по- этому выдвинутая гипотеза о влиянии факторов пола, возраста, мобильности и образования на развитие (или упадок) региональной лексики может быть отвергнута. Как видно из анализов, сегодня не существует особого различия в употреблении городской регионально маркированной лексики в речи разных поколений тверичей и обе проверенные возрастные группы используют регионализмы наравне с общеупотребительными словами литературного языка. Можно с определенной долей уверенности сделать вывод, что на сегодня регионализмы в речи жителей Твери относительно стабильны. Нельзя говорить, что регионально окрашенная лексика города уходит из употребления, как это было предположено изначально.

По результатам второго опроса окончательно прояснился региональный статус небольшого списка отобранных тверских регионализмов: именно жители Твери используют эти слова, носители других региональных норм верно определяют тверское происхождение этих лексических единиц и указывают на отсутствие их в своей речи. Это важный результат, так как большинство из проверяемых регионализмов не зафиксированы где-либо в словарях или списках, и изначально не было стопроцентной уверенности, что все регионализмы относятся к тверской региональной лексике. Относительно самой разработки опросника можно сказать, что метод контрольного списка дал удовлетворительные результаты: градация ответов давала достаточную свободу для выбора информанта и в дальнейшем была удобна для подготовки данных для анализа. Анкета информанта также имела свои преимущества и недостатки. В целом вопросы о поездках и каникулах, которые потом объединялись в своеобразный коэффициент мобильности (см.: [20]), были поставлены успешно, в отличие от менее успешных вопросов о происхождении родителей и дружеских отношениях. Эти вопросы должны были обеспечить данные по параметру «социальные сети», которые, как утверждают некоторые ученые, также влияют на развитие регионально окрашенной лексики: «Вот уже на протяжении многих лет мы стараемся показать, что сильные неформальные социальные связи внутри сообщества создают механизмы, позволяющие говорящим сохранять свои нестандартные диалекты, сельские и городские, несмотря на сильнейшее давление со стороны стандартного языка через такие каналы влияния, как образовательная система и СМИ. Мы пытались оценить эти социальные структуры количественно в терминах социальных связей. Наш анализ хорошо согласуется с представлением о том, что на речевое поведение оказывают воздействие различные «языковые рынки» [21. С. 187]. Однако в анкете первого опроса эти вопросы не были сформулированы достаточно четко, и потому ответы на них не могли быть использованы в анализе. Таким образом, метод выявления параметра социальный сетей еще требует детальной разработки.

\section{ЛИТЕРАТУРА}

1. Беликов В.И. Что такое лексический регионализм? URL: //http://forum.lingvo.ru/actualthread.aspx?bid=26\&tid=69828\&hl=\%ec\%ee\%fl

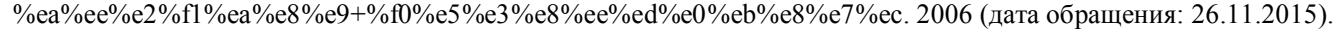


2. Китайгородская М.В., Розанова Н.Н. Языковое существование современного горожанина: На материале языка Москвы. М. : Языки славянских культур, 2010. 496 с.

3. Беликов В.И. Сравнение Петербурга с Москвой и другие соображения по социальной лексикографии // Русский язык сегодня. Вып. 3. Проблемы русской лексикографии. М., 2004. С. 23-38.

4. Матвеев А.И. Опыт комплексного описания региональной лексики (на материале регионализмов г. Новосибирска и Новосибирской области) // Научная электронная библиотека «Киберленинка». URL: //http://cyberleninka.ru/article/n/opyt-kompleksnogo-opisaniya-regionalnoyleksiki-na-materiale-regionalizmov-g-novosibirska-i-novosibirskoy-oblasti. 2009 (дата обращения: 12.12.2015).

5. Оглезнева Е.А. Дальневосточный региолект русского языка: особенности формирования // Русский язык в научном освещении. М., 2008. № 2 (16). С. 119-136.

6. Букринская И.А., Кармакова О.Е. Языковая ситуация в малых городах России // Исследования по славянской диалектологии. Особенности сосуществования диалектной и литературной форм языка в славяноязычной среде. М. : Ин-т славяноведения РАН, 2012 . № 15. С. $153-164$.

7. Ливинская И., Матвеев А.И. Словарь региональной лексики и народных топонимов города Новосибирска. Новосибирск : Свиньин и сыновья, 2015. $160 \mathrm{c.}$

8. Тематический словарь тверских городов / под ред. Т.В. Кирилловой, Л.Н. Новиковой: в 5 т. Вып.1-5. Тверь : Золотая буква, $2002-2006$.

9. Герд А.С. Введение в этнолингвистику : курс лекций и хрестоматия. СПб. : Изд-во СПб. ун-та, 2001. 488 с.

10. Резвухина Ю.А. Регионализм: к определению понятия // Научная электронная библиотека «Киберленинка». URL: //http://cyberleninka.ru/article/n/regionalizm-k-opredeleniyu-ponyatiya. 2015 (дата обращения: 12.12.2015).

11. Drake J.A. The Effect of Urbanization on Regional Vocabulary // American Speech. 1961. Vol. 36 (1). P. 17-33.

12. Pederson L., Cassidy F. Chicago Words : The Regional Vocabulary // American Speech. 1971. Vol. 36 (3/4). P. $163-192$.

13. Violin-Wigent A. Regional vocabulary levelling: The example of south-eastern French // Journal of Sociolinguistics. 2007. Vol. 11 (3). P. 408422.

14. Городские диалекты. URL: // https://forum.lingvolive.com/cat/126/ (дата обращения: 20.12.2015).

15. Словарь русского языка / под ред. А.П. Евгеньевой: в 4 т. М. : Рус. яз.; Полиграфресурcы, 1999. URL: // http://feb-web.ru/feb/mas/masabc/default.asp (дата обращения: 25.12.2015).

16. Беликов В.И., Евсеева И.В., Славкина И.А., Степанова Ф.В. Диалектная и региональная лексика : курс лекций. Красноярск, 2008.145 с.

17. Голомидова М.В. Урбанонимы в контексте культуры современного города // Ежегодник Научно-исследовательского института русской культуры. Екатеринбург : УрГУ, 1995. С. 76-86.

18. Bowie D., Yaeger-Dror M. Phonological Change in Real Time // Oxford Handbook of Historical Phonology. Oxford : Oxford University Press, 2015. P. 603-618.

19. Алпатов В.М. Языковая ситуация в регионах современной России // Отечественные записки. М., 2005. № 2 (23). С. $210-219$.

20. Labov W. The Effect of Social Mobility on Linguistic Behavior// Sociological Inquiry. 1996. Vol. 36 (2). P. $186-203$.

21. Милрой Дж., Милрой Л. Механизмы изменений в городских диалектах: роль класса, социальных сетей и гендера // Социолингвистика и социология языка. СПб. : Изд-во Европейского университета в Санкт-Петербурге, 2012. С. 183-205.

Статья представлена научной редакцией «Филология» 25 августа 2018 г.

\section{SOCIOLINGUISTIC RESEARCH INTO THE REGIONAL VOCABULARY OF TVER}

Vestnik Tomskogo gosudarstvennogo universiteta - Tomsk State University Journal, 2018, 435, 29 -39. DOI: $10.17223 / 15617793 / 435 / 4$

Olga A. Kultepina, Higher School of Economics (Moscow, Russian Federation). E-mail: okultepina@hse.ru Keywords: regional vocabulary; city-specific vocabulary; regionalism; regiolekt; sociolinguistics.

The article analyses the data of a sociolinguistic experiment that was conducted in 2015-2016 among the citizens of Tver, Moscow and St. Petersburg. The aim of the research was the regional vocabulary of Tver (Tver regionalisms, Tver local vocabulary). The term means geographically specified words used by the citizens of Tver and "marked" in their speech. The author aimed to test the hypothesis which claimed that some extralinguistic social factors (such as gender, age, mobility and education) had impact on the recognition of regional vocabulary and its usage in Tver citizens' speech, especially among the youth. Moreover, another aim was to verify the current condition of the local vocabulary in Tver. The regional vocabulary of Tver has never been studied before from a sociolinguistic point of view, though there was some similar research in other regions (Novosibirsk, Vyatka, Pskov) and it often targeted a concrete social group. A sociolinguistic questionnaire was the leading method in the research; it consisted of the questionform (with questions about age, gender, origin etc.) and two check-lists. The experiment was implemented in two steps. Each stage had its own question-form and check-lists which were presented to two different samples of informants. The first sample was made up of only Tver citizens (divided in two groups: younger than 25 years old and older than 25 years old). The second sample consisted of young women who lived in Tver, Moscow and St. Petersburg. The data were analyzed in the statistical program R (the main instrument was regression analysis) so that to reveal the correlation between social factors, usage and recognition of Tver regionalisms. The author came to the following conclusions: (a) no extralinguistic factors of the initial hypothesis influenced the usage of local vocabulary so that it could be called a significant impact, the older generation and the younger generation of Tver both used and recognized 'their' regionalisms in a very similar way; (b) the regional vocabulary of Tver still functions today, it is included in the regional norm and is recognized by speakers from other regions (Moscow, St. Petersburg), and is used by Tver citizens in their everyday speech; (c) the model of the experiment (sociolinguistic two-staged questionnaire with a check-list) can be reputed as a satisfying one, yet more concrete questions to display the influence of some social factors that formed the parameter "Social Nets" can reveal more statistically significant results.

\section{REFERENCES}

1. Belikov, V.I. (2006) Chto takoe leksicheskiy regionalizm? [What is lexical regionalism?]. [Online] Available from: http://forum.lingvo.ru/actualthread.aspx?bid=26\&tid=69828\&hl=\%ec\%ee \%fl \%ea \%ee \%e2\%fl \%ea $\%$ e $8 \%$ e $9+\%$ f0 $\%$ e $5 \%$ e3 $\%$ e $8 \%$ ee $\%$ ed $\%$ e $0 \%$ eb $\%$ e8\% $7 \%$ ec. (Accessed: 26.11.2015).

2. Kitaygorodskaya, M.V. \& Rozanova, N.N. (2010) Yazykovoe sushchestvovanie sovremennogo gorozhanina: Na materiale yazyka Moskvy [The linguistic existence of the modern citizen: Based on the language of Moscow]. Moscow: Yazyki slavyanskikh kul'tur.

3. Belikov, V.I. (2004) Sravnenie Peterburga s Moskvoy i drugie soobrazheniya po sotsial'noy leksikografii [Comparison of Petersburg with Moscow and other considerations on social lexicography]. In; Krysin, L.P. (ed.) Russkiy yazyk segodnya [Russian language today]. Is. 3. Moscow: Russian Language Institute, RAS. 
4. Matveev, A.I. (2009) Opyt kompleksnogo opisaniya regional'noy leksiki (na materiale regionalizmov g. Novosibirska i Novosibirskoy oblasti) [The experience of a complex description of regional vocabulary (on the material of regionalisms of Novosibirsk and Novosibirsk Oblast)]. [Online] Available from: http://cyberleninka.ru/article/n/opyt-kompleksnogo-opisaniya-regionalnoy-leksiki-na-materiale-regionalizmov-g-novosibirska-inovosibirskoy-oblasti. (Accessed: 12.12.2015).

5. Oglezneva, E.A. (2008) Dal'nevostochnyy regiolekt russkogo yazyka: osobennosti formirovaniya [Far Eastern Regiolect of the Russian language: features of the formation]. Russkiy yazyk v nauchnom osveshchenii. 2 (16). pp. 119-136.

6. Bukrinskaya, I.A. \& Karmakova, O.E. (2012) Yazykovaya situatsiya v malykh gorodakh Rossii [The language situation in small cities of Russia]. In: Issledovaniya po slavyanskoy dialektologii. Osobennosti sosushchestvovaniya dialektnoy $i$ literaturnoy form yazyka $v$ slavyanoyazychnoy srede [Studies in Slavic dialectology. Features of the coexistence of the dialect and literary forms of language in the Slavic-speaking environment]. Is. 15. Moscow: Institute of Slavic Studies, RAS. pp. 153-164.

7. Livinskaya, I. \& Matveev, A.I. (2015) Slovar' regional'noy leksiki i narodnykh toponimov goroda Novosibirska [Dictionary of regional vocabulary and folk place names of Novosibirsk]. Novosibirsk: Svin'in i synov'ya.

8. Kirillova, T.V \& Novikova, L.N. (eds) (2002-2006) Tematicheskiy slovar' tverskikh gorodov: $v 5 t$. [Thematic dictionary of Tver cities: in 5 vols]. Tver: Zolotaya bukva.

9. Gerd, A.S. (2001) Vvedenie v etnolingvistiku: kurs lektsiy i khrestomatiya [Introduction to ethnolinguistics: lectures and anthology]. St. Petersburg: St. Petersburg State University.

10. Rezvukhina, Yu.A. (2015) Regionalizm: $k$ opredeleniyu ponyatiya [Regionalism: on the definition of the concept]. [Online] Available from: http://cyberleninka.ru/article/n/regionalizm-k-opredeleniyu-ponyatiya. (Accessed: 12.12.2015).

11. Drake, J.A. (1961) The Effect of Urbanization on Regional Vocabulary. American Speech. 36 (1). pp. $17-33$.

12. Pederson, L. \& Cassidy, Fund (1971) Chicago Words: The Regional Vocabulary. American Speech. 36 (3/4). pp. 163-192.

13. Violin-Wigent, A. (2007) Regional vocabulary levelling: The example of south-eastern French. Journal of Sociolinguistics. 11 (3). pp. $408-422$. DOI: $10.1111 / \mathrm{j} .1467-9841.2007 .00330 . \mathrm{x}$

14. Lingvolive.com. (n.d.) Gorodskie dialekty [Urban dialects]. [Online] Available from: https://forum.lingvolive.com/cat/126/. (Accessed: 20.12.2015).

15. Evgen'eva, A.P. (ed.) (1999) Slovar' russkogo yazyka: v 4 t. [Dictionary of the Russian language: in 4 vols]. Moscow: Rus. yaz.; Poligrafresursy, [Online] Available from: http://feb-web.ru/feb/mas/mas-abc/default.asp. (Accessed: 25.12.2015).

16. Belikov, V.I., Evseeva, I.V., Slavkina, I.A. \& Stepanova, F.V. (2008) Dialektnaya i regional'naya leksika: kurs lektsiy [Dialect and regional vocabulary: lectures]. Krasnoyarsk: [s.n.].

17. Golomidova, M.V. (1995) Urbanonimy v kontekste kul'tury sovremennogo goroda [Urbanonyms in the context of the culture of the modern city]. In: Matveev, A.K. et al. (eds) Ezhegodnik Nauchno-issledovatel'skogo instituta russkoy kul'tury [Yearbook of the Research Institute of Russian Culture]. Ekaterinburg: Ural State University. pp. 76-86.

18. Bowie, D. \& Yaeger-Dror, M. (2015) Phonological Change in Real Time. In: Honeybone, P. \& Salmons, J. (eds) Oxford Handbook of Historical Phonology. Oxford: Oxford University Press.

19. Alpatov, V.M. (2005) Yazykovaya situatsiya v regionakh sovremennoy Rossii [The language situation in the regions of modern Russia]. Otechestvennye zapiski. 2 (23). pp. 210-219.

20. Labov, W. (1996) The Effect of Social Mobility on Linguistic Behavior. Sociological Inquiry. 36 (2). pp. 186-203. DOI: 10.1111/j.1475682X.1966.tb00624.x

21. Milroy, J. \& Milroy, L. (2012) Mekhanizmy izmeneniy v gorodskikh dialektakh: rol' klassa, sotsial'nykh setey i gendera [Mechanisms of change in urban dialects: the role of class, social network and gender]. Translated from English. In: Vakhtin, N.B. (ed.) Sotsiolingvistika $i$ sotsiologiya yazyka [Sociolinguistics and sociology of language]. St. Petersburg: European University in St. Petersburg. 